\title{
Antiepileptic Drugs Prevent Seizures in Hyperbaric Oxygen: \\ A Novel Model of Epileptiform Activity
}

Ivan T. Demchenko, ${ }^{1,2,4}$ Sergei Yu Zhilyaev, ${ }^{4}$ Alexander N. Moskvin, ${ }^{4}$ Alexander I. Krivchenko, ${ }^{4}$ Claude A. Piantadosi, ${ }^{1,2,3}$ Barry W. Allen ${ }^{1,2}$ *

\section{KEYWORDS:}

Antiepileptic Drugs, CNS Oxygen Toxicity, Oxidative Stress, Reactive Oxygen and Nitrogen

Species, Nitric Oxide, Epileptiform Seizures

\section{ABBREVIATIONS:}

$\mathbf{H B O}_{2}$ (Hyperbaric Oxygen), ATA (Atmospheres Absolute), AED (Antiepileptic Drug), CBZ (Carbamazepine), GBP (Gabapentin), LTG (Lamotrigine), OXC (Oxcarbazepine), PRM (Primidone), TGB (Tiagabine), VGB (Vigabatrin), VPA (Valproic Acid), ZNS (Zonisamide) 


\section{ABSTRACT [250 words]}

Breathing oxygen at sufficiently elevated pressures can trigger epileptiform seizures. Therefore, we tested the hypothesis that pre-treatment with FDA-approved antiepileptic drugs could prevent seizure onset in hyperoxia at 5 atmospheres absolute. We selected drugs from two putative functional categories, $\mathrm{Na}^{+}$-channel antagonists and GABA enhancers, each administered intraperitoneally at four doses in separate groups of C57BL/6 mice. The drugs varied in efficacy at the doses used. Of the five tested $\mathrm{Na}^{+}$-channel antagonists, carbamazepine and lamotrigine more than tripled seizure latency compared to values seen in vehicle controls. Primidone, zonisamide and oxcarbazepine were less effective. Of the four GABA reuptake inhibitors, tiagabine and vigabatrin also increased seizure latency by more than three times control values; valproic acid was less effective, and the GABA synthesis promoter gabapentin was intermediate in effectiveness. We infer that $\mathrm{Na}^{+}$-channel function and GABA neurotransmission may be critical targets in the pathophysiology of $\mathrm{CNS} \mathrm{O}_{2}$ toxicity. Because these essential components of neuronal excitation and inhibition are also implicated in the pathogenesis of other seizure disorders, including generalized epilepsy, we propose that, at some level, common pathways are involved in these pathologies, although the initiating insults differ. Furthermore, hyperoxic exposures are not known to cause the spontaneously-recurring seizures that characterize true clinical epilepsy. Nonetheless, experimental studies of hyperbaric oxygen toxicity could provide new insights into molecular mechanisms of seizure disorders of various etiologies. In addition, the neuropathology of hyperbaric oxygen is particularly relevant to the hypothesis held by some investigators that oxidative stress is an etiological factor in clinical epilepsies. 


\section{INTRODUCTION}

Oxygen is a convulsant when breathed for a sufficient time at partial pressures of 2.5 atmospheres absolute (ATA) or above, and latency to onset of epileptiform patterns on the EEG and tonic-clonic neuromotor responses is inversely proportional to inspired $\mathrm{Po}_{2}$. This has been well established in human and animal studies that have been conducted for many years, primarily to devise procedures for protecting personnel exposed to hyperbaric oxygen $\left(\mathrm{HBO}_{2}\right)$ in certain occupational and therapeutic environments (Balentine, 1982; Behnke et al., 1935; Clark and Thom, 2003; Donald, 1947a; Donald, 1947b; Paton, 1967). Vulnerable groups include military and civilian divers, crew attempting escape from a disabled submarine and patients undergoing hyperbaric oxygen therapy.

Although many drugs have been developed to prevent seizures of various etiologies, particularly those of broad clinical relevance, none have been specifically formulated to protect against seizures in $\mathrm{HBO}_{2}$, and it is unlikely that pharmaceutical companies would undertake the research needed to do so, since the human population at risk is small. Up to now, the only reliable methods for avoiding neurotoxicity in $\mathrm{HBO}_{2}$ have been to limit the dose and duration of hyperbaric oxygenation.

Although the events or conditions that initiate seizures in hyperbaric oxygen and in other seizure disorders may differ, the final common pathways and ultimate molecular targets may be similar. Indeed, some investigators have proposed that oxidative stress plays a contributory role in epilepsy (Patel, 2004; Pearson et al., 2015; Zsurka and Kunz, 2015). We reasoned, therefore,

that antiepileptic drugs (AEDs) could prevent or delay seizures of $\mathrm{CNS}_{2}$ toxicity and as a corollary, AEDs with known mechanisms-of-action might be used as investigative probes to further elucidate events that evoke hyperoxic seizures, although the true mechanisms of action of some of these drugs are not completely understood and may not fit neatly into their nominal functional classes. Furthermore, if a broad range of AEDs are found to prevent or delay seizures 
in $\mathrm{HBO}_{2}$, and if there are parallels between the ictal events in $\mathrm{HBO}_{2}$ and those seen in other seizure disorders, the hyperbaric model could elucidate mechanisms of various seizure-related disorders, including those due to the acquired and idiopathic epilepsies, traumatic brain injury and other causes. However, it must be understood that most animal models used in epilepsy research only simulate the seizures of epilepsy rather than epilepsy itself (Loscher, 2011), and this would apply to $\mathrm{HBO}_{2}$ as well.

In this study we assessed the ability of nine FDA-approved AEDs, administered individually, to increase seizure latency in mice exposed to $100 \%$ oxygen at 5 ATA for 60 min. This level and duration of hyperoxia reliably elicits seizures in this species in a reasonable period of time (60 min or less) without producing a significant degree of direct cardiopulmonary injury (Demchenko et al., 2007).

Since abnormal propagation of excitatory neurotransmission and attenuation of inhibitory neurotransmission are established pathogenic factors in clinical epilepsies (Jefferys, 2010) and are also assumed to be factors in $\mathrm{CNS} \mathrm{O}_{2}$ toxicity (Colton and Colton, 1982; Dean et al., 2003; Demchenko and Piantadosi, 2006), we chose to evaluate the protective efficacy in $\mathrm{HBO}_{2}$ of AEDs from two functional classes relevant to excitatory and inhibitory functions: sodiumchannel antagonists and GABA transmission enhancers. We compared our findings with published values for the efficacy of the same AEDs in a well-established animal model of epileptic seizures, maximal electroshock (MES). 


\section{RESULTS}

Seizure Activity in Vehicle-Treated Mice. The 24 mice treated with vehicle $(0.9 \%$ $\mathrm{NaCl}$ or DMSO) and exposed to $\mathrm{HBO}_{2}$ at 5 ATA exhibited neuromotor responses that progressed in 2 or 3 stages, comparable to those of the Racine Scale (Racine, 1972). In stage I, restlessness, intensive grooming, slight tremors, twitching vibrissae and transient muscular spasms were observed. In stage II, persistent, rhythmic spasms appeared in the face and body along with bilateral forelimb clonus and escape behaviors. Stage III, if it occurred, was characterized by generalized tonic-clonic convulsions. Stages I and II were seen in 23 (>95\%) of the vehicletreated mice; one mouse was unresponsive. All three stages occurred in $17(>70 \%)$ of these animals. In the remaining 7 (29\%) vehicle-treated mice, stage III was not seen; instead, the signs of stage II suddenly disappeared and behavioral arrest was observed for the remainder of the 60min exposure. For the purpose of evaluating the efficacy of AEDs, we defined the termination of seizure latency to coincide with either the first signs of stage II or with behavioral arrest, either of which would incapacitate human subjects and therefore mark the limit of safe exposure to $\mathrm{HBO}_{2}$.

Seizure Activity in AED-Treated Mice. Each of the tested AEDs delayed the onset of $\mathrm{CNS} \mathrm{O}_{2}$ toxicity in a dose-dependent fashion (Table 1, Figures 1 and 2). However, almost all of these animals exhibited either signs of stage II or behavioral arrest at some point during a 60-min exposure. Stage III was observed in $47 \%$ of these animals, mostly those treated with lower doses. Of the Na-channel antagonists, carbamazepine (CBZ) and lamotrigine (LTG) were the most effective, increasing seizure latency by more than three times that observed in animals treated with vehicle; whereas primidone (PRM), zonisamide (ZNS) and oxcarbazepine (OXC) were least

effective, and at the lowest doses used they failed to increase seizure latency significantly $(P \leq$ 0.05), compared to vehicle controls. 
Of the GABA transmission enhancers, the reuptake inhibitors tiagabine (TGB) and vigabatrin (VGB) were the most effective, increasing seizure latency by more than three times compared to vehicle controls, when administered at the highest doses. Valproic acid (VPA) was the least effective. The GABA-synthesis promoter gabapentin (GBP) was intermediate in effectiveness. Only VGB provided significant increases in seizure latency at the lowest dose.

Equally-effective Doses. To provide a uniform standard for evaluating efficacy, we used linear regression analysis $\left(\mathrm{R}^{2}>0.95\right.$ in all cases) to predict an equally-effective dose (EQD) for each AED that would increase seizure latency by a fixed multiple of the mean latency observed in the corresponding vehicle controls (Figures $3 \mathrm{~A}$ and $3 \mathrm{C}$ ). Because the $\mathrm{Na}^{+}$-channel antagonists LTG and CBZ and the GABA enhancers VGB and TGB each increased latency by more than a factor of 3, we selected $\mathrm{EQD}_{3 \mathrm{x}}$ as a convenient standard for comparison. For the other 5 drugs, this parameter was estimated by extrapolation along the calculated lines of best fit. This procedure was validated by comparison with $\mathrm{ED}_{50}$ 's obtained using log Probit Analysis (Litchfield and Wilcoxon, 1949). Since the latter method assumes all-or-none responses, latency data from the first 40 minutes of each hyperbaric exposure were used, an interval in which some animals exhibited seizure activity and some did not. For each drug, we found good qualitative agreement between the $\mathrm{EQD}_{3 \mathrm{x}}$ and the $\mathrm{ED}_{50}$. 


\section{DISCUSSION}

We have demonstrated that a range of FDA-approved AEDs, of two functional classes, can significantly delay seizure onset in extreme hyperoxia. Although other investigators have tested the protective efficacy of two such drugs in $\mathrm{HBO}_{2}, \mathrm{CBZ}$ and VGB (Bitterman and Halpern, 1995; Hall et al., 2013; Harel et al., 1978; Reshef et al., 1991; Tzuk-Shina et al., 1991), we know of no study in which the anticonvulsant efficacies of multiple AEDs were compared in hyperbaric hyperoxia.

Among the $\mathrm{Na}^{+}$-channel antagonists we tested, CBZ and LTG were the most effective in increasing seizure latency and exhibited the highest potencies, as shown in Figure 3A. Clinically, CBZ is considered "first line anticonvulsant therapy for generalized tonic-clonic and partial seizures" (Reinikainen et al., 1987), whereas LTG is used as initial therapy for focal epilepsy, idiopathic generalized epilepsy and absence seizures in children (Biton et al., 2005; Coppola et al., 2004). Both of these drugs impose use-dependent blocks on neuronal sodium channels during rapid, repetitive, sustained firing (Clemens et al., 2007; Goldenberg, 2010; Vreugdenhil and Wadman, 1999). LTG may also inhibit neuronal synthesis of glutamate and aspartate, diminishing the release of these excitatory neurotransmitters (Lee et al., 2008).

The remaining $\mathrm{Na}^{+}$-channel antagonists, OXC, ZNS, and PRM, were less effective in $\mathrm{HBO}_{2}$ but still doubled seizure latency when administered in high doses. OXC and ZNS are used clinically to treat both focal and generalized seizures in adults and children, but not generalized tonic-clonic seizures (Goldenberg, 2010; Kothare et al., 2004). The mode of action of OXC is comparable to that of CBZ, imposing a use-dependent blockade of sodium channels (Reinikainen et al., 1987). ZNS, however, is chemically and structurally unrelated to the other AEDs, and its primary mechanism of action is to block both voltage-dependent sodium channels and T-type calcium channels (Goldenberg, 2010; Leppik, 2004). As for PRM, its mode of action is difficult to study as such, since it is converted to phenobarbital, phenylethylmalonamide (PEMA) and 
several other metabolites; it may act by imposing a use-dependent blockade of voltage-gated sodium channels and by increasing GABA-mediated chloride influx (Lasoń et al., 2011).

Of the GABA-enhancing AEDs we tested, TGB and VGB were the most effective and had the highest potencies. TGB increases GABA concentration in the synaptic cleft by inhibiting its reuptake, and it is used clinically as an adjunctive treatment for focal seizures (Ängehagen et al., 2003; Lasoń et al., 2013). VGB irreversibly inhibits the degradation of GABA by GABAtransaminase and is used to treat refractory focal seizures (Thomas et al., 1996) and as a monotherapy (Aicardi et al., 1996). The other GABA-enhancers, GBP and VPA, significantly increased seizure latency in $\mathrm{HBO}_{2}$ only at high doses. GBP elevates GABA levels in the brain by an unknown mechanism and although structurally similar to GABA, it is not known to act directly on GABA receptors. VPA may increase GABA synthesis by stimulating glutamate decarboxylase (GAD) activity. It also modulates voltage-gated sodium currents during sustained, rapid, repetitive neuronal firing (Taverna et al., 1998).

Our finding that certain $\mathrm{Na}^{+}$-channel antagonists and GABA-enhancers provide a sustained anticonvulsant effect in extreme hyperoxia supports our hypothesis that, at some level, similar molecular targets are involved in $\mathrm{HBO}_{2}$-neurotoxicity and in other seizure disorders for which the efficacies of these drugs have been established clinically. Indeed, a correlation between $\mathrm{Na}^{+}$-channel activation and increased neuronal firing has been documented in $\mathrm{HBO}_{2}$ (Garcia et al., 2003; Mulkey et al., 2003). Likewise, the role of diminished inhibitory neurotransmission in $\mathrm{HBO}_{2}$ seizures has been well described (Colton and Colton, 1982; Colton and Colton, 1986; Colton and Colton, 1978). Clearly, certain drugs that beneficially modulate neuronal function in other seizure disorders also protect against hyperoxic seizures. It is thought-provoking that the pattern of relative efficacy of most of the drugs we tested ${ }^{1}$, when

\footnotetext{
${ }^{1}$ VGB is excluded from this comparison because it is ineffective in the MES model (Loscher et al., 1994; Waszkielewicz et al., 2011).
} 
plotted in order of increasing $\mathrm{ED}_{50}$, closely resembles that seen for the same drugs administered to mice subjected to maximal electroshock, MES (Bialer et al., 2004), when doses are expressed as molar equivalents (Chmielewska and Lamparczyk, 2008) (Table 2 and Figure 4). The difference in magnitudes of the $\mathrm{ED}_{50}$ 's for the two experimental models is likely due to the fact that the intensities of the two kinds of stimuli are unequal. Perhaps a lower $\mathrm{Po}_{2}$, for example 3 ATA, would result in a closer correspondence in doses, something to be determined by investigators who may wish to pursue the parallels between these two experimental models.

From our results, we infer that AEDs with specific mechanisms-of-action can be used as tools to investigate mechanisms of $\mathrm{CNS} \mathrm{O}_{2}$ toxicity. This inference, however, is limited by the fact that the true mechanisms of action of some of these drugs may not fit neatly into their nominal classes. For example, some ostensible $\mathrm{Na}^{+}$-channel antagonists may enhance GABA neurotransmission and inhibit that of glutamate, for example PRM. Other $\mathrm{Na}^{+}$-channel antagonists may also block L-type or T-type $\mathrm{Ca}^{2++}$ channels. The polyspecificity of certain AEDs has been extensively reviewed (Czapinski et al., 2005; Fariello, 1993; Lasoń et al., 2011; Sills and Brodie, 2001).

Our findings also support the idea that $\mathrm{HBO}_{2}$ could be added to the list of established techniques (Grone and Baraban, 2015; Raol and Brooks-Kayal, 2012; Rogawski, 2006) used to elicit epileptiform seizures in animal models. It must be said, however, that the epileptiform events seen in $\mathrm{CNS}_{2}$ toxicity are not strictly speaking "epilepsy", since that term implies the spontaneous recurrence of seizures. Yet if a comparison is to be made, which form of clinical epilepsy most closely parallels $\mathrm{CNS} \mathrm{O}_{2}$ toxicity? The idea that reactive oxygen and nitrogen species (RONS) are produced uniformly throughout the brain would support the view that CNS oxygen toxicity begins in both hemispheres and, therefore, most closely resembles primary generalized epilepsy. However, cerebral blood flow, oxidative metabolism and the concentration of antioxidant enzymes exhibit significant differences in various brain regions (Allen et al., 
2009; Demchenko and Piantadosi, 2006; Demchenko et al., 2012). This is consistent with a multifocal initiation of seizure activity in $\mathrm{HBO}_{2}$ and the concept that hyperoxic seizures are partial seizures with secondary generalization.

Hyperbaric oxygen, therefore, has interesting properties as a convulsant. For example, administration by inhalation does not involve the stresses induced in conscious animals by capture and injection of a drug or placement of stimulating electrodes. Also, oxygen is a lipophilic gas that diffuses readily to target tissues, assuring rapid kinetics of distribution (Micarelli et al., 2013). Finally, the stages of seizure progression-including prodromal phases and recruitment of neurons beyond an initial focus - can be studied in isolation by a careful titration of the inspired $\mathrm{Po}_{2}$ which can be achieved by adjusting the pressure in the hyperbaric chamber, without having to alter the concentration of $\mathrm{O}_{2}$ in the inspired gas. In our previous work, we have exploited these characteristics to delineate several pathophysiological states that precede the onset of hyperoxic seizures, by exposing rodents to levels of $\mathrm{HBO}_{2}$ ranging from 3 to 6 ATA. These preliminary phases include sequential changes in the afferent and efferent limbs of the autonomic nervous system, cardiovascular function, EEG, and neuromotor responses (Allen et al., 2009; Demchenko and Piantadosi, 2006; Demchenko et al., 2012).

A relatively new hypothesis of epilepsy pathogenesis is that oxidative stress is a factor in epileptic seizure initiation (Martinc et al., 2012; Patel, 2004; Waldbaum and Patel, 2010). Therefore, the seizures of $\mathrm{CNS} \mathrm{O}_{2}$ toxicity could provide an appropriate model for direct investigation of redox-dependent mechanisms by which neuronal hyperexcitability and hypersynchrony might develop. A large body of work in the hyperbaric literature demonstrates that reactive oxygen and nitrogen species (ROS and RNS) interact with the machinery of neuronal excitation and synaptic transmission. Thus, the activation of diatomic oxygen by an initial one-electron reduction to the superoxide anion $\left(\cdot \mathrm{O}_{2}^{-}\right)$that occurs in mitochondria and at other enzymatic sites, as well as the endogenous production of nitric oxide (NO·) are both 
increased in $\mathrm{HBO}_{2}$. In the thermodynamically-favored events that follow, other reactive oxygen and nitrogen species are generated, including hydrogen peroxide $\left(\mathrm{H}_{2} \mathrm{O}_{2}\right)$, the hydroxyl radical $\left(\mathrm{OH}^{*}\right)$ and peroxynitrite $\left(\mathrm{ONOO}^{-}\right)\left(\mathrm{D}^{\prime}\right.$ Agostino et al., 2007; Demchenko et al., 2003). The brief half-life of these reactive species limits their scope of action, but where their sources of production are intimately co-located with redox-sensitive neuronal targets, significant alterations in membrane excitability and neurotransmission can occur. For example, ion-sensitive and voltage-sensitive channels that regulate permeability to $\mathrm{Na}^{+}, \mathrm{K}^{+}$and $\mathrm{Ca}^{2+}$ all present potential targets (Matalon et al., 2003; Mulkey et al., 2003), as do the mechanisms involved in the biosynthesis, re-uptake and metabolism of neurotransmitters. In this regard, GABA is particularly important, as there are multiple redox-sensitive targets in its pathways of synthesis, release, uptake and catabolism. Alterations in these processes can perturb the equilibrium between excitation and inhibition in specific brain regions, resulting in increased neuronal firing that propagates across brain structures (Demchenko and Piantadosi, 2006). Ultimately, increased oxidative and nitrosative stresses that occur in $\mathrm{HBO}_{2}$ drive excessive neuronal excitation that results in epileptiform patterns on the EEG and tonic-clonic neuromotor responses (Allen et al., 2009; D'Agostino et al., 2007; Demchenko et al., 2001; Demchenko et al., 2005).

The amino acid cysteine is a critical constituent at many functional sites in the CNS and is particularly vulnerable to both ROS and RNS through S-oxidation and S-nitrosylation, and both of these processes are intensified in $\mathrm{HBO}_{2}$. Thus, cysteine residues in the beta-1 subunit of voltage-gated $\mathrm{Na}^{+}$-channels form a stabilizing disulfide bridge, and its disruption can lead to certain idiopathic epilepsies (Wallace et al., 1998). Likewise, calcium-activated BK-type $\mathrm{K}^{+}$ channels contain cysteine string proteins, consisting of multiple linked cysteines, which have critical regulatory functions (Kyle et al., 2013). Also, the so-called Cys-loop super-family of receptors includes acetylcholine, 5- $\mathrm{HT}_{3}$, glycine and $\mathrm{GABA}_{\mathrm{a}}$ receptors (Connolly and Wafford, 
2004; Pan et al., 2000). Furthermore, signals mediated through cysteine oxidation regulate key mitochondrial functions, in the CNS and elsewhere (Mailloux et al., 2014). The cysteines in these examples, as well as those in other critical locations in the CNS, are all potentially subject to oxidative or nitrosative attack.

Conclusions. The findings presented here support our hypothesis and its corollary: a range of FDA-approved AEDs can prevent or delay seizures in extreme hyperoxia, and AEDs with known mechanisms-of-action can serve as investigative probes to elucidate seizure mechanisms in $\mathrm{HBO}_{2}$. Thus, some of the AEDs we tested increased seizure latency to more than triple that observed in vehicle controls. Furthermore, the significant protective efficacy in $\mathrm{HBO}_{2}$ of AEDs known to block $\mathrm{Na}^{+}$-channel function or to enhance GABA-mediated inhibition clearly demonstrate that $\mathrm{Na}^{+}$-channel function and GABA neurotransmission are critical targets of hyperbaric oxygen and, by implication, are significant nodes on pathways to CNS toxicity. By extension, since disturbances of $\mathrm{Na}^{+}$-channel function and GABA-mediated inhibition are also implicated in other seizure disorders; the body of information that has been accrued by the many studies of CNS toxicity in $\mathrm{HBO}_{2}$ may be useful well beyond the traditional fields of hyperbaric medicine and physiology. In addition, hyperbaric oxygen is particularly well-suited to pursue the hypothesis that oxidative stress is a contributive factor in some forms of epilepsy. 


\section{GRANTS}

This work was supported by the Office of Naval Research Grant N00014-15-1-2072 (to C. A.

Piantadosi) and the Russian Federation for Basic Research Grant 15-04-05970 (to I. T.

Demchenko). 


\section{METHODS and MATERIALS}

Experiments were performed on conscious C57BL/6 mice (weighing 19-25g and approximately 2.5 months in age) at the Center for Hyperbaric Medicine and Environmental Physiology, Duke University Medical Center (Durham, NC, USA), and at the Institute of Evolutionary Physiology and Biochemistry, Russian Academy Sciences (St. Petersburg, Russia). Animal use protocols were approved independently by the Institutional Animal Care and Use Committee of Duke University and the Ethical Review Board of the Institute of Evolutionary Physiology and Biochemistry. The drugs, hyperbaric exposures, assessments of animal responses and methods for analyzing results were the same at both experimental sites.

Hyperbaric Exposures. Groups of 4 to 6 freely-moving mice, selected at random, were placed in a hyperbaric chamber in separate cages. Compression to 5 ATA was accomplished at $0.7 \mathrm{ATA} \cdot \mathrm{min}^{-1}$, and exposures to $100 \% \mathrm{O}_{2}$ lasted for up to $60 \mathrm{~min}$. Chamber temperature and relative humidity were maintained at $23 \pm 0.5^{\circ} \mathrm{C}$ and $60 \pm 2 \%$. Animals were continuously observed for signs of $\mathrm{CNS} \mathrm{HBO}_{2}$ toxicity, and in some cases video recordings were made for later review.

Experimental Design. AEDs included $5 \mathrm{Na}^{+}$-channel antagonists and 4 GABA enhancers, each of which was administered in four different doses in separate groups of animals. Two additional groups were used as vehicle controls. Each treatment or control group comprised 12 animals. A total of 456 mice were used in the 36 treatment groups and the $\mathrm{NaCl}$ and DMSO vehicle controls. AEDs were obtained in clinical formulations, crushed to powder, if necessary, and dissolved in $0.9 \% \mathrm{NaCl}$ or DMSO, according to their solubilities. Prepared stock solutions were diluted so that the intended dose $\left(\mathrm{mg} \cdot \mathrm{kg}^{-1}\right)$ could be administered IP in a volume of 0.005 $\mathrm{ml} \cdot \mathrm{g}^{-1}$ body weight. The range of doses and the time allowed for onset of action for each drug were based on known pharmacokinetics, clinical practice, animal models of epilepsy (Bialer et al., 2004) and our preliminary testing of some of the drugs. 
Estimation of Efficacy. For each dose of a drug, we evaluated mean seizure latency, the time interval that began when chamber pressure reached the target pressure of 5 ATA and ended when persistent, rhythmic spasms, bilateral forelimb clonus or escape behaviors first appeared. To estimate relative efficacies, we used linear regression analysis of mean seizure latencies (expressed as multiples of latencies observed in vehicle controls) plotted against $\log _{10}$ doses to estimate an equally-effective dose (EQD) for each drug.

Statistical Analysis. Mean seizure latencies observed after pretreatment with each drugdose combination were compared with those observed in the corresponding vehicle controls using 2-way ANOVA. Significance was accepted at $P \leq 0.05$. 


\section{REFERENCES}

Aicardi, J., et al., 1996. Vigabatrin as initial therapy for infantile spasms: A European retrospective survey. Epilepsia. 37, 638-642.

Allen, B.W., et al., 2009. Two faces of nitric oxide: implications for cellular mechanisms of oxygen toxicity. J. Appl. Physiol. 106.

Ängehagen, M., et al., 2003. Novel mechanisms of action of three antiepileptic drugs, vigabatrin, tiagabine, and topiramate. Neurochemical Research. 28, 333-340.

Balentine, J.D., 1982. Pathology of oxygen toxicity. Vol., Academic Press, New York.

Behnke, A.R., et al., 1935. The effect of oxygen on man at pressures from 1 to 4 atmospheres. American Journal of Physiology. 110, 565-572.

Bialer, M., et al., 2004. Correlation analysis between anticonvulsant ED50 values of antiepileptic drugs in mice and rats and their therapeutic doses and plasma levels. Epilepsy \& Behavior. 5, 866-872.

Biton, V., et al., 2005. Double-blind, placebo-controlled study of lamotrigine in primary generalized tonic-clonic seizures. Neurology. 65, 1737-1743.

Bitterman, N., Halpern, P., 1995. The Effect of Flumazenil on Cns Oxygen-Toxicity in the Rat. Methods and Findings in Experimental and Clinical Pharmacology. 17, 169-174.

Chmielewska, A., Lamparczyk, H., 2008. Mass versus molar doses, similarities and differences. Pharmazie. 63, 843-848.

Clark, J.M., Thom, S.R., 2003. Oxygen under pressure. In Bennett and Elliott's Physiology and medicine of diving. Vol., A.O. Brubakk, T.S. Newman, ed.^eds. Edinburgh ; New York Saunders, pp. 358-418.

Clemens, B., et al., 2007. Lamotrigine decreases EEG synchronization in a use-dependent manner in patients with idiopathic generalized epilepsy. Clinical Neurophysiology. 118, 910-917. 
Colton, C.A., Colton, J.S., 1982. An electrophysiological analysis of oxygen and pressure on synaptic transmission. Brain Res. 251, 221-7.

Colton, C.A., Colton, J.S., 1986. The Action of Oxygen and Oxygen at High-Pressure on Inhibitory Transmission. Brain Research. 364, 151-158.

Colton, J.S., Colton, C.A., 1978. Effect of Oxygen at High-Pressure on Spontaneous Transmitter Release. American Journal of Physiology. 235, C233-C237.

Connolly, C.N., Wafford, K.A., 2004. The Cys-loop superfamily of ligand-gated ion channels: the impact of receptor structure on function. Biochemical Society Transactions. 32, 529534.

Coppola, G., et al., 2004. Lamotrigine as first-line drug in childhood absence epilepsy: a clinical and neurophysiological study. Brain \& Development. 26, 26-29.

Czapinski, P., et al., 2005. Mechanisms of action of antiepileptic drugs. Current Topics in Medicinal Chemistry. 5, 3-14.

D'Agostino, D.P., et al., 2007. Superoxide $\left(\cdot \mathrm{O}_{2}{ }^{-}\right)$production in CA1 neurons of rat hippocampal slices exposed to graded levels of oxygen. Journal of Neurophysiology. 98, 1030-1041.

Dean, J.B., et al., 2003. Neuronal sensitivity to hyperoxia, hypercapnia, and inert gases at hyperbaric pressures. Journal of Applied Physiology. 95, 883-909.

Demchenko, I.T., et al., 2001. Nitric oxide production is enhanced in rat brain before oxygeninduced convulsions. Brain Res. 917, 253-261.

Demchenko, I.T., et al., 2003. Oxygen seizure latency and peroxynitrite formation in mice lacking neuronal or endothelial nitric oxide synthases. Neuroscience Letters. 344, 53-56.

Demchenko, I.T., et al., 2005. Cerebral blood flow and brain oxygenation in rats breathing oxygen under pressure. J Cereb Blood Flow Metab. 25, 1288-1300. 
Demchenko, I.T., Piantadosi, C.A., 2006. Nitric oxide amplifies the imbalance of excitatory to inhibitory neurotransmission accelerating oxygen seizures. Undersea Hyperbar. Med. 33, 169-174.

Demchenko, I.T., et al., 2007. Similar but not the same: normobaric and hyperbaric pulmonary oxygen toxicity--the role of nitric oxide. AJP Lung. 00450.2006.

Demchenko, I.T., et al., 2012. Nitric oxide-mediated central sympathetic excitation promotes CNS and pulmonary O2 toxicity. Journal of Applied Physiology. 112, 1814-1823.

Donald, K.W., 1947a. Oxygen Poisoning in Man: Part I. British Medical Journal. 1, 667-672.

Donald, K.W., 1947b. Oxygen Poisoning in Man: Part II. British Medical Journal. 1, 712-717.

Fariello, R.G., 1993. Mechanisms of Action of Antiepileptic Drugs. Epileptogenic and Excitotoxic Mechanisms. 8, 41-49.

Garcia, A.J., et al., 2003. Oxidative stress induced by hyperbaric oxygen increases the synaptic response of CA1 neurons in the rat hippocampus. In FASEB Science Research Conference. Vol. 17, ed.^eds., San Diego, CA., pp. A71.

Goldenberg, M.M., 2010. Overview of Drugs Used For Epilepsy and Seizures: Etiology, Diagnosis, and Treatment. Pharmacy and Therapeutics. 35, 392-415.

Grone, B.P., Baraban, S.C., 2015. Animal models in epilepsy research: legacies and new directions. Nat Neurosci. 18, 339-343.

Hall, A.A., et al., 2013. Vigabatrin prevents seizure in swine subjected to hyperbaric hyperoxia. Journal of Applied Physiology. 115, 861-867.

Harel, D., et al., 1978. Influence of a Gaba Transaminase Inhibitor on Central Nervous-System OxygenToxicity. Aviation Space and Environmental Medicine. 49, 877-879.

Jefferys, J.G.R., 2010. Advances in understanding basic mechanisms of epilepsy and seizures. Seizure. 19, 638-646. 
Kothare, S.V., et al., 2004. Efficacy and tolerability of zonisamide in juvenile myoclonic epilepsy. Epileptic Disorders. 6, 267-270.

Kyle, B.D., et al., 2013. The Large Conductance, Calcium-activated K+ (BK) Channel is regulated by Cysteine String Protein. Scientific Reports. 3, 2447.

Lasoń, W., et al., 2013. Research advances in basic mechanisms of seizures and antiepileptic drug action. Pharmacological Reports. 65, 787-801.

Lasoń, W., et al., 2011. Basic mechanisms of antiepileptic drugs and their pharmacokinetic/pharmacodynamic interactions: an update. Pharmacological Reports. 63, 271-292.

Lee, C.Y., et al., 2008. Lamotrigine inhibits postsynaptic AMPA receptor and glutamate release in the dentate gyrus. Epilepsia. 49, 888-897.

Leppik, I.E., 2004. Zonisamide: chemistry, mechanism of action, and pharmacokinetics. SeizureEuropean Journal of Epilepsy. 13, S5-S9.

Litchfield, J.T., Wilcoxon, F., 1949. A Simplified Method of Evaluating Dose-Effect Experiments. Journal of Pharmacology and Experimental Therapeutics. 96, 99-113.

Loscher, W., 2011. Critical review of current animal models of seizures and epilepsy used in the discovery and development of new antiepileptic drugs. Seizure-European Journal of Epilepsy. 20, 359-368.

Macdougall, J., 2006. Analysis of Dose-Response Studies-Emax Model. In Dose Finding in Drug Development. Vol., N. Ting, ed.^eds. Springer New York, New York, NY, pp. 127145.

Mailloux, R.J., et al., 2014. Redox regulation of mitochondrial function with emphasis on cysteine oxidation reactions. Redox Biology. 2, 123-139. 
Martinc, B., et al., 2012. The Role of Reactive Species in Epileptogenesis and Influence of Antiepileptic Drug Therapy on Oxidative Stress. Current Neuropharmacology. 10, 328343.

Matalon, S., et al., 2003. Regulation of ion channel structure and function by reactive oxygennitrogen species. American Journal of Physiology - Lung Cellular and Molecular Physiology. 285, L1184-L1189.

Micarelli, A., et al., 2013. Neurobiological insight into hyperbaric hyperoxia. Acta Physiologica. 209, 69-76.

Mulkey, D.K., et al., 2003. Pressure ( $\leq 4$ ATA) increases membrane conductance and firing rate in the rat solitary complex. Journal of Applied Physiology. 95, 922-930.

Pan, Z.H., et al., 2000. Redox modulation of recombinant human $\mathrm{GABA}_{\mathrm{A}}$ receptors. Neuroscience. 98, 333-338.

Patel, M., 2004. Mitochondrial dysfunction and oxidative stress: cause and consequence of epileptic seizures. Free Radical Biology and Medicine. 37, 1951-1962.

Paton, W.D., 1967. Experiments on the convulsant and anaesthetic effects of oxygen. $\mathrm{Br} \mathrm{J}$ Pharmacol Chemother. 29, 350-66.

Pearson, J.N., et al., 2015. Reactive oxygen species mediate cognitive deficits in experimental temporal lobe epilepsy. Neurobiology of Disease. 82, 289-297.

Racine, R.J., 1972. Modification of Seizure Activity by Electrical Stimulation .2. Motor Seizure. Electroencephalography and Clinical Neurophysiology. 32, 281-\&.

Raol, Y.H., Brooks-Kayal, A.R., 2012. Experimental Models of Seizures and Epilepsies. Animal Models of Molecular Pathology. 105, 57-82.

Reinikainen, K.J., et al., 1987. Comparison of oxcarbazepine and carbamazepine: a double-blind study. Epilepsy Research. 1, 284-289. 
Reshef, A., et al., 1991. The effect of carbamazepine and ethosuximide on hyperoxic seizures. Epilepsy Research. 8, 117-121.

Rogawski, M.A., 2006. Molecular Targets Versus Models for New Antiepileptic Drug Discovery. Epilepsy research. 68, 22-28.

Sills, G.J., Brodie, M.J., 2001. Update on the mechanisms of action of antiepileptic drugs. Epileptic Disorders. 3, 165-172.

Taverna, S., et al., 1998. Valproate selectively reduces the persistent fraction of $\mathrm{Na}^{+}$current in neocortical neurons. Epilepsy Res. 32, 304-8.

Thomas, L., et al., 1996. Vigabatrin and behaviour disorders: a retrospective survey. Epilepsy Res. 25, 21-7.

Tzuk-Shina, T., et al., 1991. The Effect of Vigabatrin on Central-Nervous-System OxygenToxicity in Rats. European Journal of Pharmacology. 202, 171-175.

Vreugdenhil, M., Wadman, W.J., 1999. Modulation of sodium currents in rat CA1 neurons by carbamazepine and valproate after kindling epileptogenesis. Epilepsia. 40, 1512-22.

Waldbaum, S., Patel, M., 2010. Mitochondrial dysfunction and oxidative stress: a contributing link to acquired epilepsy? J Bioenerg Biomembr. 42, 449-55.

Wallace, R.H., et al., 1998. Febrile seizures and generalized epilepsy associated with a mutation in the $\mathrm{Na}^{+}$-channel $\beta 1$ subunit gene SCN1B. Nat Genet. 19, 366-370.

Zsurka, G., Kunz, W.S., 2015. Mitochondrial dysfunction and seizures: the neuronal energy crisis. The Lancet Neurology. 14, 956-966. 


\section{FIGURE LEGENDS}

Figures 1 and 2: Seizure Latencies for Conscious Mice exposed to $\mathrm{HBO}_{2}$ at 5 ATA, after pretreatment with one of 2 functional classes of AEDs administered individually at 4 different doses, are shown as multiples of latencies seen in mice treated with vehicle controls. $\mathrm{Na}^{+}$Channel Antagonists: PRM (Primidone), ZNS (Zonisamide), OXC (Oxcarbazepine), LTG (Lamotrigine), and $\boldsymbol{C B Z}$ (Carbamazepine). GABA Enhancers: $\boldsymbol{V P A}$ (Valproic Acid), GBP (Gabapentin), $\boldsymbol{V G B}$ (Vigabatrin), and $\boldsymbol{T} \boldsymbol{G B}$ (Tiagabine). Statistically significant differences ( $p \leq$ 0.05) among maximally-effective doses are indicated with linked tick marks.

Figure 3: Equally-effective doses (EQD's) and $\mathrm{ED}_{50}$ 's in $\mathrm{HBO}_{2}$ at 5 ATA.

A and C. Regression lines $\left(\mathrm{R}^{2}>0.95\right)$ are plotted as mean seizure latencies (expressed as multiples of latencies in vehicle controls) against $\log _{10}$ AED doses. Broken lines intersect regression curves at each point where the corresponding dose is predicted to produce seizure latency $3 \mathrm{x}$ that observed in vehicle controls.

B and D. Estimated $\mathrm{ED}_{50}$ 's are obtained by plotting mean seizure latencies (expressed as probability units, probits) against $\log _{10}$ AED doses. Broken lines intersect dose-response curves at each point where the corresponding dose results in the probability that half of the treated animals will experience seizures and half will not.

$\mathrm{Na}^{+}$Channel Antagonists: O LTG (Lamotrigine), $\square \mathrm{CBZ}$ (Carbamazepine), $\triangle \mathrm{OXC}$ (Oxcarbazepine), ZNS (Zonisamide) and PRM (Primidone).

GABA Enhancers: $\diamond \boldsymbol{T G B}$ (Tiagabine), $\square \mathrm{GBP}, \triangle \boldsymbol{V G B}$ (Vigabatrin), $\bigcirc \mathrm{VPA}$ (Valproic Acid), 
Figure 4: The pattern of $\mathrm{ED}_{50}$ 's for 8 AEDs in mice exposed to $\mathrm{HBO}_{2}$ at 5 ATA closely tracks with that of the same drugs tested in mice using the maximal electroshock (MES) model, when normalized $\mathrm{ED}_{50}$ doses are expressed in molar values. 


\section{FIGURES}

Figure 1

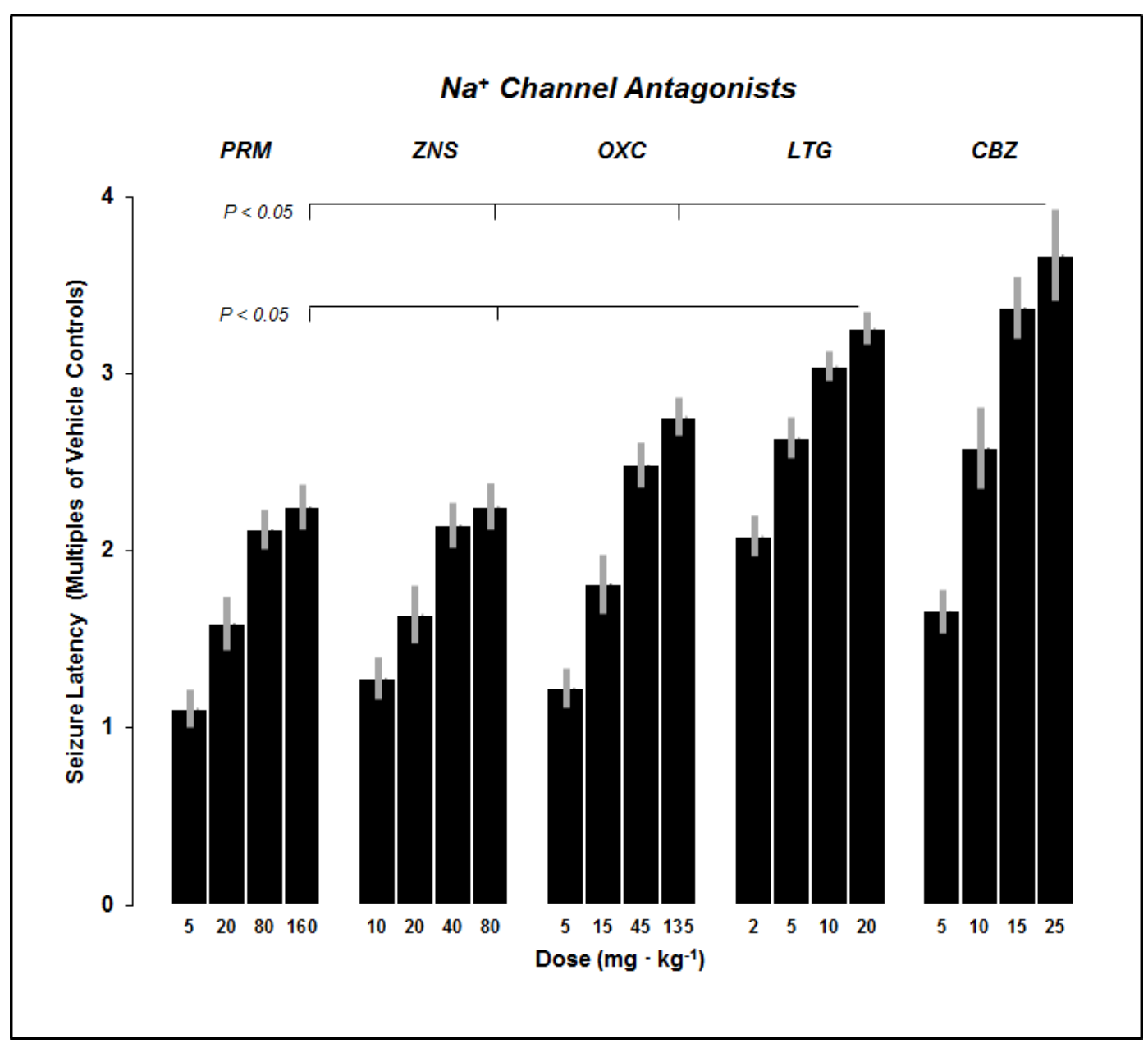

50

51

52

53

54

55

56

57

58

59

60

61

62

63

64

65 
Figure 2

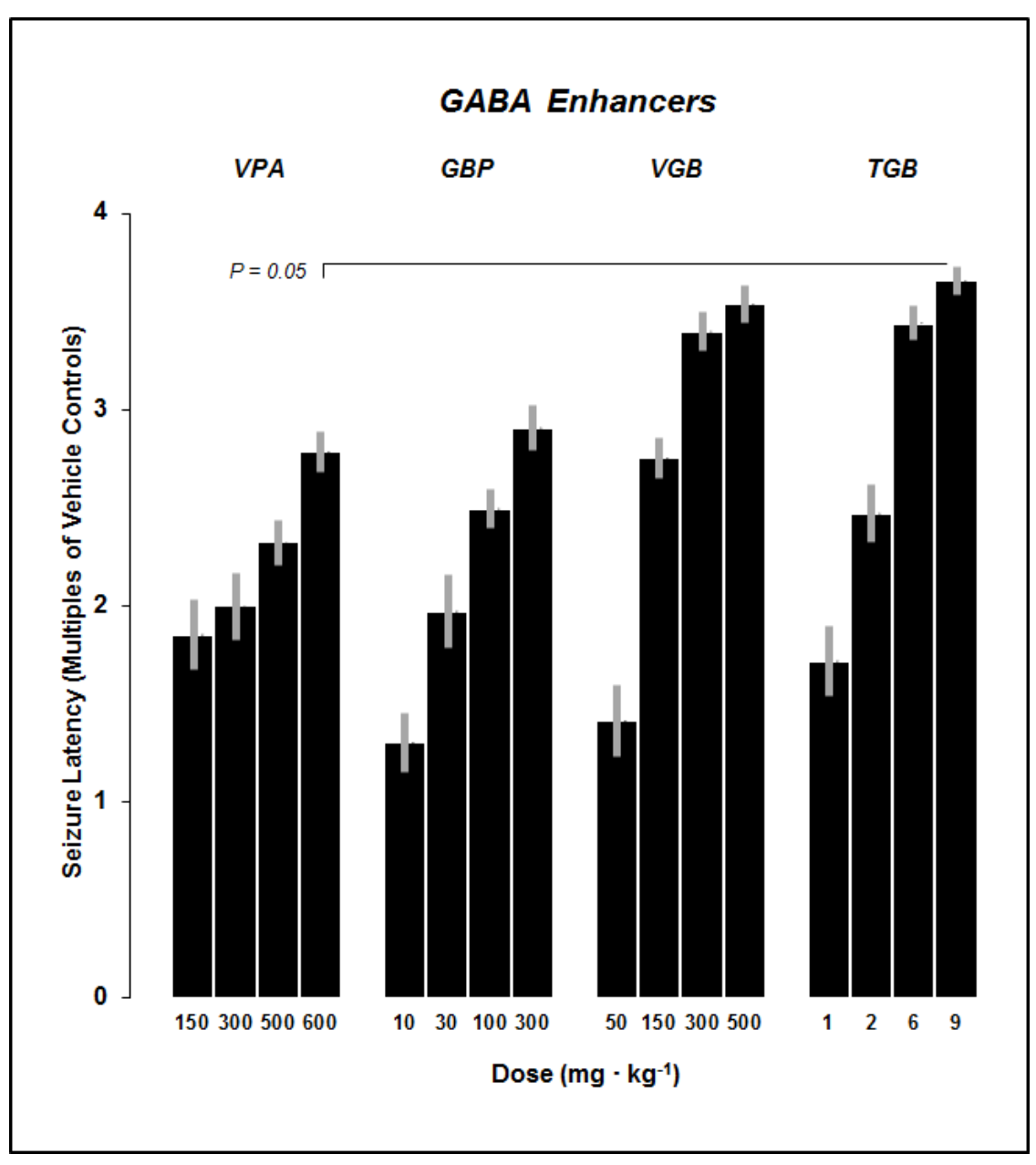

49

50

51

52

53

54

55

56

57

58

59

60

61

62

63

64

65 
Figure 3

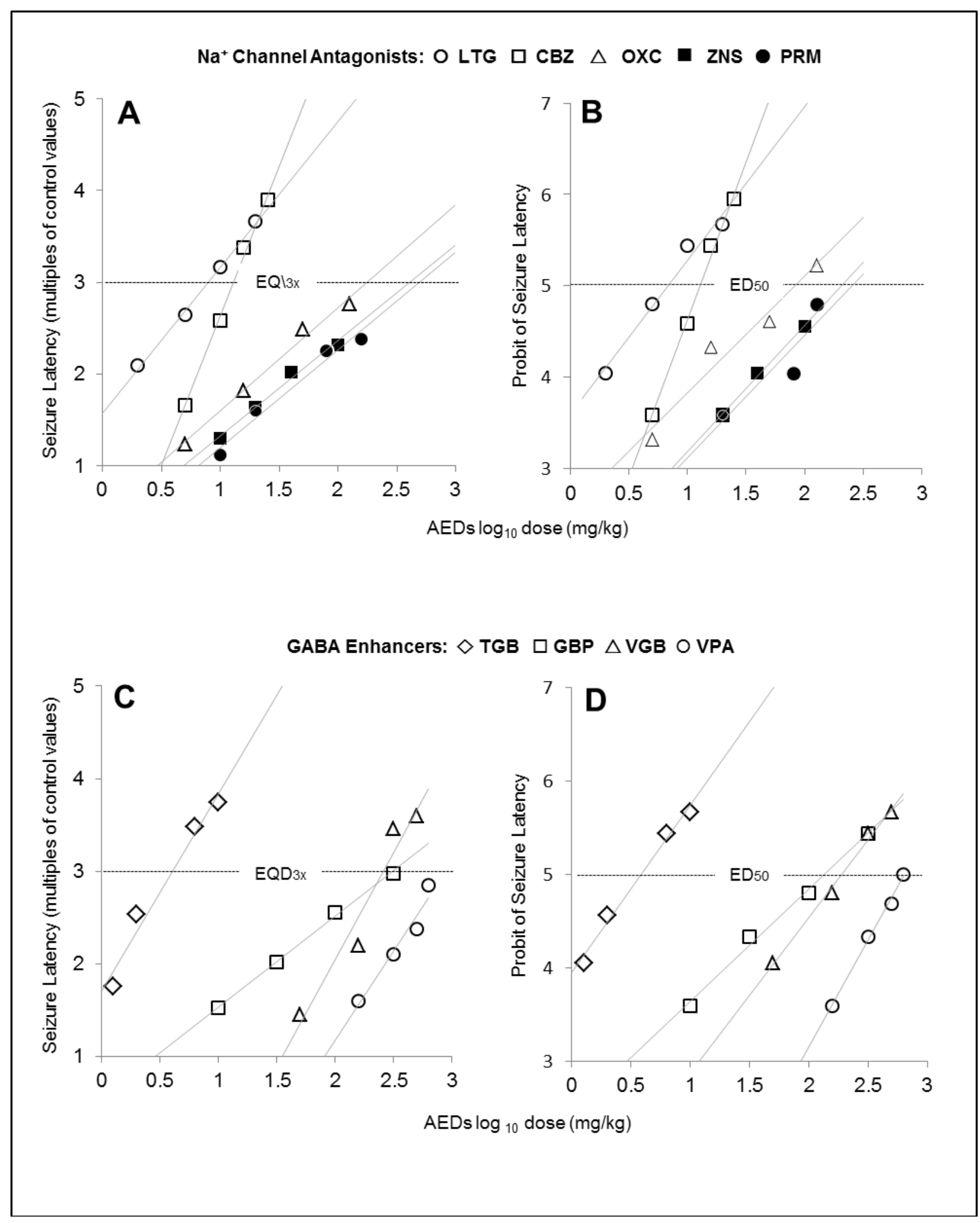

60

61

62

63 
Figure 4

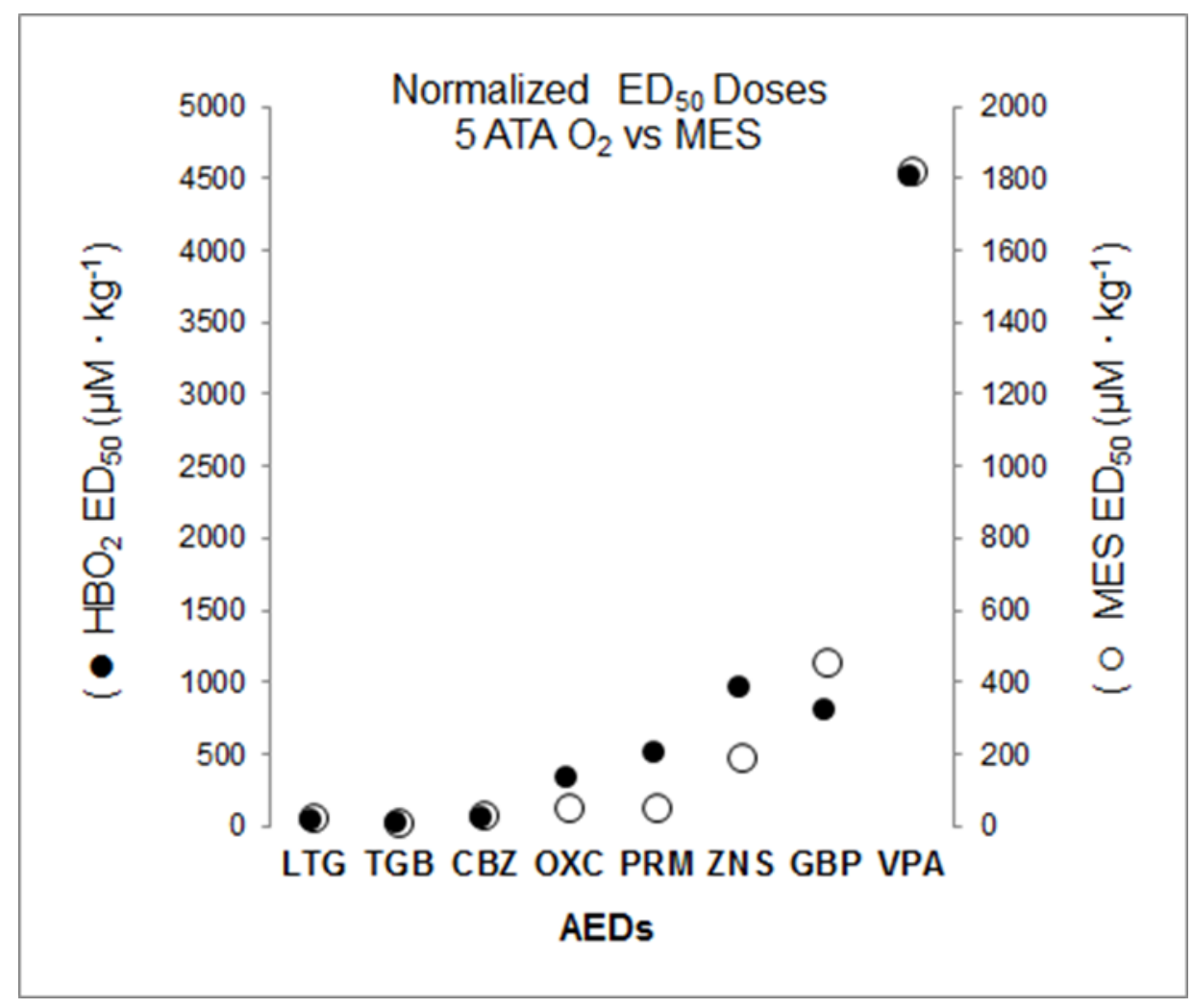




\section{TABLES}

Table 1: Effects of AED/dose Combinations vs Vehicle in $\mathrm{HBO}_{2}$ at 5 ATA

\begin{tabular}{|c|c|c|c|c|c|c|}
\hline $\begin{array}{c}\text { AEDs } \\
\text { [Vehicle] }\end{array}$ & $\begin{array}{c}\text { AEDs } \\
\text { Dose } \\
\left(\mathrm{mg} \cdot \mathrm{kg}^{-1}\right)\end{array}$ & $\begin{array}{c}\text { Numbers } \\
\text { of } \\
\text { Mice }\end{array}$ & $\begin{array}{l}\text { Time Allowed } \\
\text { for Onset of } \\
\text { Action (Min) }\end{array}$ & $\begin{array}{c}\text { Mean } \\
\text { Seizure } \\
\text { Latency (Min) }\end{array}$ & $\begin{array}{l}\text { Standard } \\
\text { Error } \\
\text { of the Mean }\end{array}$ & $\begin{array}{c}\text { Significance } \\
\text { vs } \\
\text { Vehicle }\end{array}$ \\
\hline \multicolumn{7}{|c|}{ VEHICLE CONTROLS } \\
\hline $\begin{array}{l}0.9 \% \mathrm{NaCl} \\
\text { DMSO }\end{array}$ & & $\begin{array}{l}12 \\
12\end{array}$ & $\begin{array}{l}60 \\
60\end{array}$ & $\begin{array}{l}12.8 \\
13.5\end{array}$ & $\begin{array}{l}1.7 \\
1.6\end{array}$ & - \\
\hline \multicolumn{7}{|c|}{$\mathrm{Na}^{+}-\mathrm{CH} A N N E L$ ANTAGONISTS } \\
\hline Carbamazepine & 5 & 12 & 60 & 22.4 & 2.7 & $* P \leq 0.03$ \\
\hline (CBZ) & 10 & 12 & & 34.8 & 3.2 & $* P \leq 0.01$ \\
\hline Tegetrol@ & 15 & 12 & & 45.6 & 2.4 & $* P \leq 0.01$ \\
\hline [DMSO] & 25 & 12 & & 49.6 & 3.6 & $* P \leq 0.01$ \\
\hline Lamotrigine & 2 & 12 & 60 & 28.2 & 3.3 & $* P \leq 0.01$ \\
\hline (LTG) & 5 & 12 & & 35.7 & 4.2 & $* P \leq 0.01$ \\
\hline Lamictaß & 10 & 12 & & 41.0 & 3.4 & $* P \leq 0.01$ \\
\hline [DMSO] & 20 & 12 & & 44.0 & 4.1 & $* P \leq 0.01$ \\
\hline Primidone & 5 & 12 & 60 & 15.0 & 2.0 & - \\
\hline (PRM) & 20 & 12 & & 21.5 & 2.4 & $* P \leq 0.03$ \\
\hline Mysoline ${ }^{\circledR}$ & 80 & 12 & & 28.7 & 2.9 & $* P \leq 0.01$ \\
\hline [DMSO] & 160 & 12 & & 30.3 & 5.0 & $* P \leq 0.01$ \\
\hline Zonisamide & 10 & 12 & 60 & 16.5 & 2.0 & - \\
\hline (ZNS) & 20 & 12 & & 21.0 & 3.5 & $* P \leq 0.03$ \\
\hline Zonegran® & 40 & 12 & & 27.6 & 3.5 & $* P \leq 0.03$ \\
\hline$[0.9 \% \mathrm{NaCl}]$ & 80 & 12 & & 28.9 & 3.9 & $* P \leq 0.01$ \\
\hline Oxcarbazepine & 5 & 12 & 60 & 16.6 & 1.8 & - \\
\hline (OXC) & 15 & 12 & & 24.5 & 4.0 & $* P \leq 0.03$ \\
\hline Trileptaß & 45 & 12 & & 33.6 & 4.1 & $* P \leq 0.01$ \\
\hline & 135 & 12 & & 37.3 & 3.9 & $* P \leq 0.01$ \\
\hline \multicolumn{7}{|c|}{ GABA ENHANCERS } \\
\hline Gabapentin & 10 & 12 & 120 & 16.8 & 2.5 & - \\
\hline (GBP) & 30 & 12 & & 25.3 & 4.7 & $* P \leq 0.01$ \\
\hline Neurontin® & 100 & 12 & & 32.0 & 3.2 & $* P \leq 0.01$ \\
\hline$[0.9 \% \mathrm{NaCl}]$ & 300 & 12 & & 37.3 & 4.2 & $* P \leq 0.01$ \\
\hline Tiagabine & 1 & 12 & 60 & 22.1 & 3.9 & - \\
\hline (TGB) & 2 & 12 & & 31.8 & 4.6 & $* P \leq 0.02$ \\
\hline Gabatril@ & 6 & 12 & & 43.6 & 3.8 & $* P \leq 0.01$ \\
\hline$[0.9 \% \mathrm{NaCl}]$ & 9 & 12 & & 46.9 & 3.3 & $* P \leq 0.01$ \\
\hline Valproic Acid & 150 & 12 & 60 & 23.8 & 4.2 & - \\
\hline (VPA) & 300 & 12 & & 25.7 & 4.4 & $* P \leq 0.03$ \\
\hline Depakene® & 500 & 12 & & 29.8 & 3.4 & $* P \leq 0.01$ \\
\hline$[0.9 \% \mathrm{NaCl}]$ & 600 & 12 & & 35.8 & 3.7 & $* P \leq 0.01$ \\
\hline Vigabatrin & 50 & 12 & 240 & 18.2 & 3.3 & $* P \leq 0.01$ \\
\hline (VGB) & 150 & 12 & & 35.3 & 3.6 & $* P \leq 0.01$ \\
\hline Sabri周 & 300 & 12 & & 43.6 & 4.3 & $* P \leq 0.01$ \\
\hline$[0.9 \% \mathrm{NaCl}]$ & 500 & 12 & & 45.4 & 4.2 & $* P \leq 0.01$ \\
\hline
\end{tabular}


Table 2: $\mathrm{ED}_{50}$ for AEDs in $5 \mathrm{ATA} \mathrm{HBO}_{2}$ vs MES

\begin{tabular}{ccccc|}
\hline AED & \multicolumn{2}{c}{$\mathrm{ED}_{50}$} & \multicolumn{2}{c|}{$\mathrm{ED}_{50}$} \\
& $\mathrm{HBO}{ }_{2} 5 \mathrm{ATA}$ & \multicolumn{2}{c}{ Max Electro Shock } \\
\hline & $\mathrm{mg} \cdot \mathrm{kg}^{-1}$ & $\mu \mathrm{M} \cdot \mathrm{kg}^{-1}$ & $\mathrm{mg} \cdot \mathrm{kg}^{-1}$ & $\mu \mathrm{M} \cdot \mathrm{kg}^{-1}$ \\
LTG & 7 & 27 & 8 & 29 \\
TGB & 3 & 8 & 5 & 12 \\
OXC & 13 & 54 & 8 & 33 \\
PRM & 82 & 325 & 14 & 57 \\
ZNS & 204 & 961 & 41 & 191 \\
GBP & 136 & 794 & 78 & 456 \\
VPA & 648 & 4,500 & 263 & 1,826 \\
VGB & 190 & 1,471 & - & - \\
\hline
\end{tabular}

